\title{
Cultura dos povos originários da floresta amazônica na gestação e no puerpério: uma revisão de escopo sob o ponto de vista da segurança alimentar e nutricional
}

\author{
Culture of people originating from the Amazon rainforest during \\ pregnancy and the puerperium: a scope review from the point of view \\ of food and nutrition security
}

\author{
Angélica Baptista Silva', lanê Germano de Andrade Filha', Katherine Mary Marcelino Benevides², \\ Deborah Moraes da Silva ${ }^{\mathbf{3}}$, Pedro Máximo de Andrade Rodrigues ${ }^{\mathbf{4}}$, Sandra Cavalcante Silva ${ }^{\mathbf{2}}$, \\ Martha Inés Camargo Garzón 5
}

DOI: 10.1590/0103-1104201912319

\begin{abstract}
RESUMO A desnutrição na população indígena é um problema de saúde pública atual e uma das principais causas de morbimortalidade das crianças desses grupos no Brasil. Para subsidiar ações de promoção da educação alimentar e nutricional, abrangendo povos da floresta do estado do Amazonas, Brasil, cujo território faz fronteira com a Colômbia, além da visita de campo em 2018, fez-se necessário, concomitantemente, mapear na literatura como essa população vive e de que maneira o cuidado é prestado. A revisão de escopo buscou tópicos referentes ao modo de vida das mulheres e crianças na Amazônia, à dieta durante o período gestacional e do puerpério, a práticas de aleitamento, à introdução de alimentos sólidos ao bebê e aos cuidados dos serviços de saúde. Como resultado, foram recuperados 21 estudos multidisciplinares. Encontrou-se que a comida tradicional tem valor nutricional maior do que a industrializada, a culinária local é uma fonte de renda das mulheres indígenas no meio urbano e um elo entre etnias. Conclui-se que as pesquisas devem incorporar o paradigma da promoção da saúde e abranger temas como a aculturação indígena nos centros urbanos amazônicos, a chegada da internet nas aldeias e o papel do cuidado à distância, que necessitam ser investigados para melhor enfrentamento do problema.
\end{abstract}

1 Fundação Oswaldo Cruz (Fiocruz), Escola Nacional de Saúde Pública Sergio Arouca (Ensp) - Rio de Janeiro (RJ), Brasil. silva.angelica@gmail.com

2 Secretaria de Estado de Saúde do Amazonas (Susam) - Manaus (AM) Brasil.

${ }^{3}$ Faculdade Martha Falcão (FMF) - Manaus (AM), Brasil.

4 Universidade do Estado do Amazonas (UEA) -

Manaus (AM), Brasil.

${ }^{5}$ Governo da

Cundinamarca - Bogotá,

Colômbia.
PALAVRAS-CHAVE Saúde de populações indígenas. Saúde da mulher. Saúde da criança. Segurança alimentar e nutricional. Telessaúde.

\begin{abstract}
Malnutrition in the indigenous population is a current public health problem and a major cause of morbidity and mortality of children in these groups in Brazil. In order to support actions to promote food and nutrition education, including forest peoples from the state of Amazonas, Brazil, whose territory borders Colombia, in addition to the field visit in 2018, it was necessary, at the same time, to map the literature as this one. Population lives and how care is provided. The scope review sought topics related to the lifestyle of women and children in the Amazon, diet during pregnancy and the postpartum period, breastfeeding practices, the introduction of solid foods to the baby, and the care of health services. As a result, 21 multidisciplinary studies were retrieved. Traditional food has been found to have higher nutritional value than industrialized food, and local cuisine is a source of income for indigenous women in the urban environment and a link between ethnicities. It is concluded that the researches should incorporate the health promotion paradigm and cover themes such as indigenous acculturation in the Amazonian urban centers, the arrival of the internet in the villages and the role of distance care, which needs to be investigated to better address the problem.
\end{abstract}

KEYWORDS Health of indigenous peoples. Women's health. Child health. Food and nutrition security. Telemedicine. 


\section{Introdução}

O estado com o maior número de indígenas no Brasil é o Amazonas, representando 55\% do total da região Norte. A literatura evidencia um perfil nutricional e antropométrico com elevadas prevalências de deficits de estatura e desnutrição nas crianças indígenas, associado a más condições socioeconômicas e ambientais'1.

A desnutrição na população indígena do País é um problema de saúde pública e uma das principais causas de morbimortalidade das crianças desses povos ${ }^{2}$. Outras causas que elevam as taxas de mortalidade indígena são as doenças infecciosas e parasitárias. A anemia, um dos agravos que acompanham a desnutrição, apresenta grande relevância no estado nutricional da população infantil. A prevalência de anemia no I Inquérito Nacional de Saúde e Nutrição dos Povos Indígenas (I INSNPI) foi de $51,2 \%$ na população infantil indígena brasileira e de $66,4 \%$ para população infantil indígena da região Norte 3 . Essa carência nutricional é mencionada pela Organização Mundial da Saúde (OMS) como um dos maiores desafios de saúde pública nos países desenvolvidos e em desenvolvimento ${ }^{4}$.

Ao mesmo tempo que se convive com casos de desnutrição e anemia, emergem os casos de sobrepeso e obesidade, principalmente entre o sexo feminino. E se as doenças infecciosas ainda continuam a ocupar um papel dominante, por outro lado, percebe-se crescimento na ocorrência de doenças crônicas não transmissíveis, tais como diabetes mellitus e hipertensão arterial. Esse cenário permite vislumbrar que os povos indígenas amazônicos estão passando por um processo de transição nutricional ${ }^{5}$.

De acordo com alguns estudos, esse processo tem ocorrido devido à acelerada adoção de alimentos ultraprocessados, em detrimento da alimentação tradicional indígena, aliada às mudanças no padrão de atividade física e inserção do hábito de fumar e consumir bebidas alcoólicas ${ }^{6}$. Os resultados apresentados no inquérito nutricional dos povos indígenas sobre o cuidado pré-natal evidenciaram condições menos satisfatórias na macrorregião Norte. Fato relevante reportado foi que o percentual de crianças que nunca foram amamentadas foi menor na região.

Frente à especificidade da promoção da saúde entre a população indígena na floresta amazônica, cujo bioma extrapola fronteiras, vislumbrou-se a necessidade de atividades de educação permanente junto aos profissionais de saúde da atenção básica e às parteiras que atuam com os povos indígenas na região, com abordagens integradas, multidisciplinares e plurinacionais.

Esta pesquisa-ação, nesse contexto, volta-se para a promoção da educação alimentar e nutricional, a adequação nutricional da população indígena, abrangendo povos da floresta do Amazonas, cujo território faz fronteira com a Colômbia. Desde 2018, são feitas palestras para os núcleos de telessaúde de todos municípios do estado do Amazonas, abordando os tópicos relacionados à estimulação para amamentação exclusiva, à melhoria das condições de saneamento e à prevenção dos casos de doenças infecciosas e parasitárias, com o intuito de promover, assim, o acesso à Segurança Alimentar e Nutricional (SAN). Porém, para realizar esta pesquisa, fez-se necessário mapear anteriormente como essa população vive e de que maneira o cuidado é prestado no território, com olhar multidisciplinar, bem como visita local em campo nos municípios de São Gabriel da Cachoeira (AM), Tabatinga (AM) e Letícia (Colômbia).

Esta revisão provém da pesquisa denominada 'Grupo de Interesse Especial Tel@ Amazônia: Avaliação da Telessaúde para Segurança Alimentar e Nutricional de mães e bebês da floresta', cujo objetivo geral é contribuir para a promoção da saúde com foco no fortalecimento da assistência à mulher e à criança nas redes de serviços de cuidados integrais à saúde, no que diz respeito à segurança alimentar e nutricional dos povos da floresta.

A finalidade da revisão é reunir subsídios para realizar os seguintes objetivos específicos: capacitar os profissionais de saúde da atenção básica e as parteiras que assistem mulheres e crianças menores de cinco anos 
para exercerem a vigilância alimentar e nutricional nos serviços de saúde; monitorar e avaliar a intervenção em telessaúde no que diz respeito à adequação nutricional da população assistida e ao aprimoramento de práticas assistenciais e contribuir para elaboração de cardápios baseados em práticas alimentares saudáveis, respeitando a diversidade cultural, e que sejam ambiental, cultural, econômica e socialmente sustentáveis.

\section{Material e métodos}

O mapeamento de literatura foi feito com base na metodologia de revisão de escopo. As Revisões de Escopo (RE) têm grande utilidade para sintetizar evidência de pesquisa. Pesquisadores recorrem a esse tipo de revisão a fim de mapear a literatura existente em termos de sua natureza, características e volume. Por isso, são chamadas, também, de revisões de mapeamento ${ }^{7}$.

As vantagens do estudo de escopo, também conhecido como scoping study ou scoping review, são identificar os principais conceitos que apoiam determinada área de conhecimento; examinar a extensão, o alcance e a natureza da investigação; sumarizar e divulgar os dados de um estudo específico e iluminar as lacunas de pesquisas existentes no tópico em questão.

Recorre-se especialmente a esse tipo de revisão de literatura para reconhecimento de áreas emergentes, também a fim de compreender as definições da pesquisa e os limites conceituais de determinado tema. Diferem-se das revisões sistemáticas por incluir documentos da literatura cinza, não indexada, inclusive relatórios de pesquisas em curso.

Adotou-se, com adaptações, o percurso metodológico recomendado pelo Instituto Joanna Briggs ${ }^{8}$ : definição da questão, critérios de elegibilidade dos documentos, definição de tipo de participantes dos estudos coletados, delineamento do conceito e contexto da revisão, escolha de base de dados para busca, preenchimento de planilha com campos de extração, leitura dos documentos recuperados por revisores duplo-cego e análise dos resultados. Sendo assim, as questões de pesquisa, que guiaram esta revisão, foram:

1. Como as gestantes, mães e bebês indígenas vivem no território amazônico?

2. Como é a cultura alimentar e nutricional de mulheres indígenas durante o período gestacional e no puerpério?

3. Como é a dieta dos bebês indígenas com idade entre 0 e 5 anos?

4. Como os profissionais da atenção básica lidam com a cultura alimentar e nutricional indígena?

Três duplas de revisores, também membros da equipe da pesquisa multidisciplinar, receberam um protocolo da revisão, um formulário com campos de extração numa planilha eletrônica e um conjunto de artigos recuperados.

Os critérios de inclusão e elegibilidade foram que a população do estudo selecionado deveria se autodeclarar indígena; morar ou percorrer (pois algumas etnias vão se deslocando pela floresta, morando temporariamente em sítios variados) dois Distritos Sanitários Especiais Indígenas (DSEI), Alto Rio Negro e Alto Rio Solimões, que estão na fronteira com a Colômbia. Documentos com profissionais de saúde também deveriam respeitar esse critério territorial. Foram coletados estudos em português, inglês e espanhol.

Quanto à tipologia de participantes dos registros recuperados, os revisores escolheram documentos cujo conteúdo envolvia:

- Mulheres indígenas no período da gestação e/ou que sejam mães de bebês de até 5 anos de idade.

- Bebês e crianças indígenas com idade entre 0 e 5 anos. 
- Profissionais de saúde (Equipes do Programa Saúde da Família, profissionais de atenção básica das unidades de saúde, profissionais da Casa de Saúde Indígena, Casai, de polos-base em aldeias e agentes indígenas de saúde), lidando diretamente com gestantes, mães e bebês de 0 a 5 anos de idade.

- Alimentação de mulheres indígenas no período da gestação e/ou que sejam mães de bebês de até 5 anos de idade.

- Alimentação de bebês e crianças indígenas na faixa de 0 a 5 anos.

O conceito disseminado aos revisores sobre essa revisão foi o processo de cuidado, envolvendo os serviços de saúde de atenção básica (pré-natal e a puericultura), a população indígena, com enfoque no aconselhamento nutricional, e a segurança alimentar, entendendo o cuidado como uma complexa trama de procedimentos e saberes em que se fundem o respeitar, $\mathrm{o}$ atender e $\mathrm{o}$ acolher o ser humano em geral, cujo sofrimento é consequência de sua fragilidade social ${ }^{9,10}$. O contexto do estudo é a saúde da mulher e da criança indígena, no que tange à SAN dos povos da floresta amazônica brasileira e colombiana.

Quanto à busca empreendida, foram rastreadas, em janeiro de 2019, as seguintes bases de dados: Pubmed/Medline, Embase, (ambas no contexto biomédico), Web of Science, Scopus e Scientific Electronic Library Online - SciELO (bases multidisciplinares), Social Service Abstracts e Literatura Latino-Americana e do Caribe em Ciências da Saúde - Lilacs (estas duas com vistas a contemplar textos oriundos das ciências sociais e da antropologia, bem como produções das institutições de pesquisa da América Latina e Caribe), sem restrição quanto a data.
Os campos de extração para os artigos foram: base de extração; autores; título; ano; periódico; tipo de publicação e idioma. $\mathrm{Na}$ planilha, havia seis perguntas sobre o estudo, sendo estas:

- Tem como objeto a população indígena amazônica?

- Tem como objeto gestantes, mães e bebês indígenas que vivem no território amazônico?

- Descreve como é a cultura alimentar e nutricional de mulheres indígenas durante a gravidez?

- Descreve como é a dieta dos bebês indígenas com idade entre 0 e 5 anos?

- Apresenta dados da região Norte do Brasil?

- Considerando os critérios de elegibilidade estabelecidos, o artigo pode ser incluído?

Cada pergunta afirmativa correspondeu a um ponto num ranking de 0 a 6 . Todos os textos pontuados foram lidos na íntegra e preenchidos nos campos resumo e destaques para revisão. Para cada questão de pesquisa, foram delineadas uma ou duas estratégias bibliométricas, com pequenas adaptações, de acordo com as bases (vide material suplementar).

\section{Resultados}

Foram selecionados e lidos na íntegra 21 documentos, sendo eles: um livro, uma dissertação de mestrado, um resumo de comunicação oral em congresso internacional, um relatório de pesquisa e 18 artigos (figura 1). 
Figura 1. Diagrama de fluxos de busca na literatura e inclusão de artigos
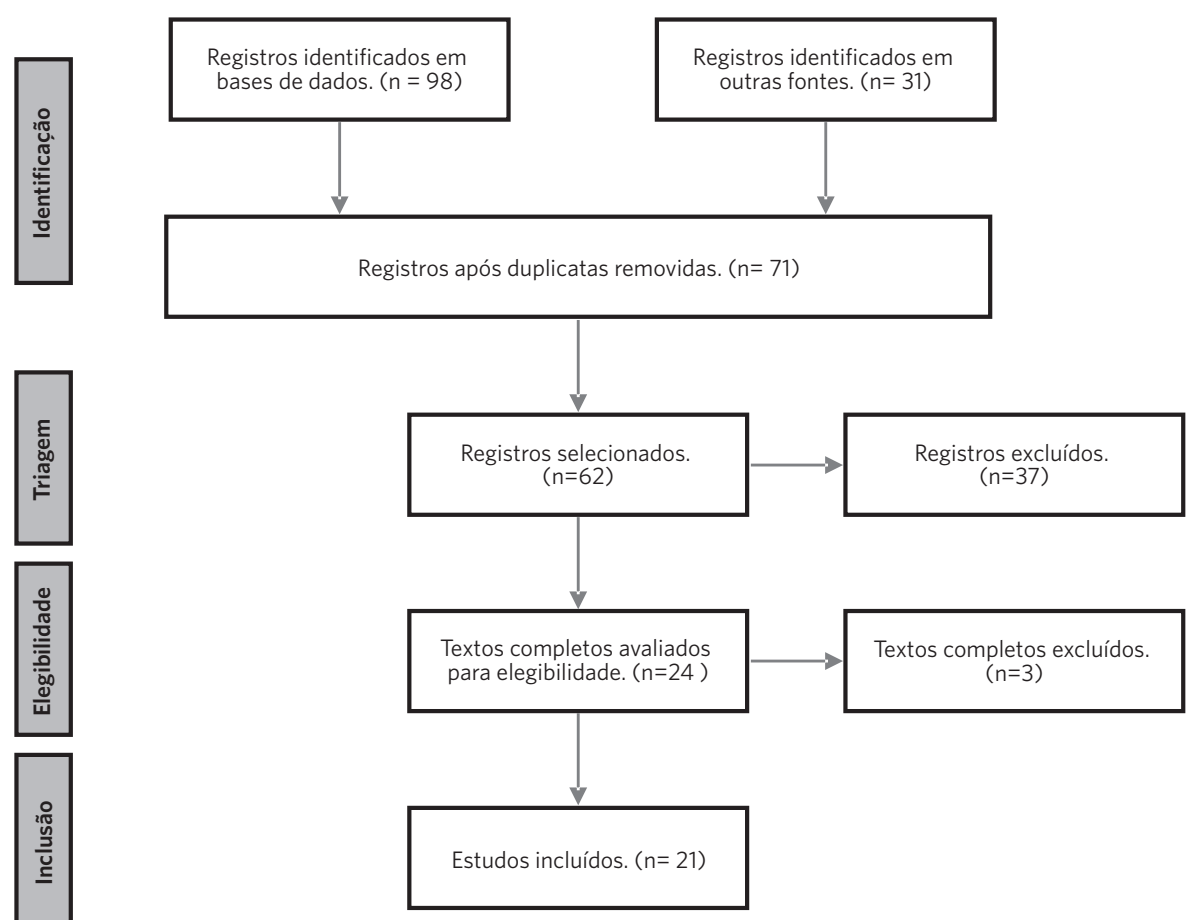

Fonte: Elaboração própria, com base em Peters MDJ et al.8

Entre os textos completos recuperados, onze foram escritos em português, oito em inglês e dois em espanhol. Quanto à densidade das quatro questões de pesquisa na literatura, pode-se obter mais informação diversificada sobre a vida da mãe e do bebê na floresta -27 ocorrências; sobre a atuação de profissionais de saúde e as metodologias de pesquisa na saúde indígena - 21; aleitamento e dieta do bebê - 11; e menos informação sobre a mulher e alimentação - 4. Vale ressaltar que houve estudos que abordaram mais de uma questão de pesquisa (figura 2). 
Figura 2. Mapeamento de eixos temáticos e fragmentos dos textos analisados em destaque

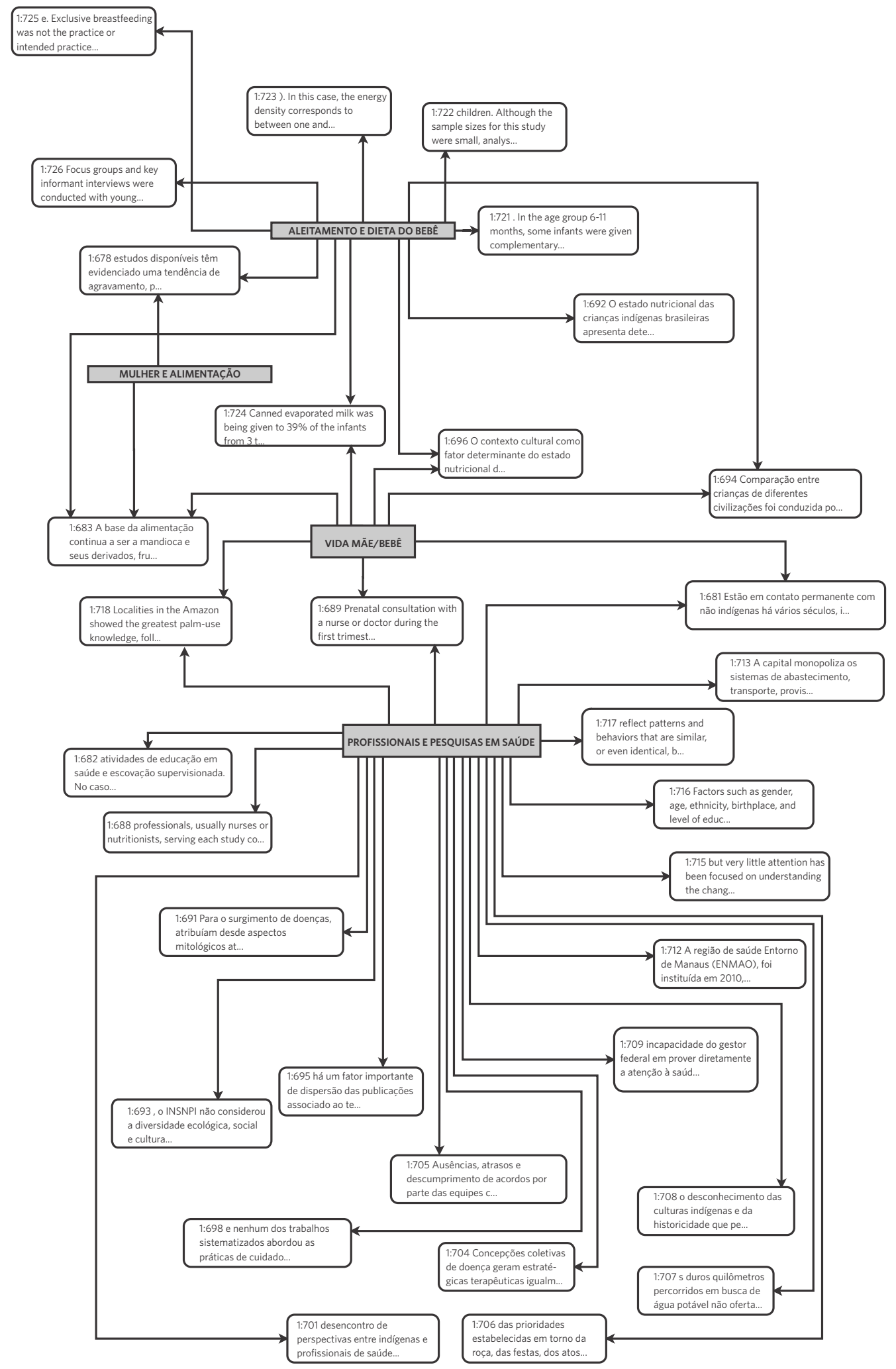


As metodologias utilizadas nos estudos selecionados (quadro 1) apontam para uma possível padronização que permite a comparação de como o conhecimento tradicional é influenciado e modificado nessas comunidades. A agregação territorial por áreas, distritos ou municípios influencia as análises, os resultados e as conclusões das pesquisas significativamente. Considerou-se, para fins de classificação, como triangulação de métodos o estudo que comporta a combinação e o cruzamento de múltiplos pontos de vista; a realização de atividades de pesquisas quantitativas e qualitativas, a fim de analisar o contexto da história, das relações e das representações e relacionar a visão de vários informantes. A triangulação implica o emprego de uma variedade de técnicas de coleta de dados, que acompanha o trabalho de investigaçãon"

Quadro 1. Quadro síntese dos artigos recuperados

\begin{tabular}{lllll}
\hline Título & Autores & País de Origem & Ano & Tipo de Estudo \\
\hline Comidas Tradicionais Indígenas do & Garnelo L, Baré, & Brasil & 2009 & $\begin{array}{l}\text { Etnográfico com pesqui- } \\
\text { Alto Rio Negro }\end{array}$ \\
GB. ação
\end{tabular}

\section{Etnias}

Baniwa, Tukano, Piratuapuia, Hupde, Tariano, Dessano, Curipako, Warekena, Tuyuka, Wanano, Cubeu, Arapaço, Yepamassã, Makunambé, Miriti tapuia, Siriano, Karapana, Maku, Barasána, Juriti, Bara, Makuna, Makuxi, Ticuna, Yanomami, Daw, Silcy-tapuya, Hupdes, Urubu

Inquérito Nacional de Saúde e Nutrição dos Povos Indígenas Condiciones de seguridad alimentaria en una comunidad indígena de Colombia

Conflict or congruence? Maternal and infant-centric factors associated with shorter exclusive breastfeeding durations among the Tsimane

Crianças indígenas brasileiras: revisão dos estudos sobre o estado nutricional
Cardd

Farfán JCC, Torres DA, Gómez MNP, Tamayo $M P Q$.

Martin MA,

Garcia G,

Kaplan HS,

Gurven MD.

Pedraza DF et al. Brasil

2014

Revisão de literatura

Transversal de base populacional nacional Colômbia

2018

Cerce

Cerca de 200 etnias

Exploratório e qualitativo Tama
Longitudinal, abordagem etnográfica com triangula- ção de métodos
EUA e México 2016

Tsimane

(1)

Aruak, Aueti, Baniwa, Baré, Calapalo, Camaiurá, Coicuro, Desana, Guaraní, Guarita, lualapiti, Kaiowá, Kamaiurá, Kayabi, Maroxewara, MatipuNafuquá,Meinaco, Munduruku, Parakanã, Paranatinga, Parkatêjê, Piratapuya, Tariana, Teréna, Teréna, Tikuna, TrumaiTrumai, Tukano, Tupí-Mondê, Uaurá, Wari', Xavante, Xingu.
Nutrition in Transition: Dietary Patterns of Rural Amazonian Women During a Period of Economic Change

Gendering local knowledge: medicinal plant use and primary health care in the Amazon

Fórum: saúde e povos indígenas no Brasil. Posfácio
Piperata BA, Ivanova SA, Veiga PDGG, Polsky A, Spence JE, Murrieta RSS.

\begin{tabular}{cccl} 
Wayland C. EUA 2001 & $\begin{array}{l}\text { Abordagem etnográfica } \\
\text { com triangulação de mé- } \\
\text { todos }\end{array}$ \\
Garnelo L. Brasil & $2014 \quad \begin{array}{l}\text { Ensaio crítico. Síntese de } \\
\text { painel científico }\end{array}$ \\
\hline
\end{tabular}

EUA, Portugale 2011 Longitudinal -

Brasil

- 


\begin{tabular}{|c|c|c|c|c|c|}
\hline Título & Autores & País de Origem & Ano & Tipo de Estudo & Etnias \\
\hline $\begin{array}{l}\text { Modernization is associated with } \\
\text { intensive breastfeeding patterns in } \\
\text { the Bolivian Amazon }\end{array}$ & $\begin{array}{l}\text { Veile A, Martin } \\
\text { M, McAllister L, } \\
\text { Gurven M. }\end{array}$ & EUA & 2014 & $\begin{array}{l}\text { Análise de base de dados e } \\
\text { pesquisa de campo etno- } \\
\text { gráfica }\end{array}$ & Tsimane \\
\hline $\begin{array}{l}\text { The First National Survey of Indige- } \\
\text { nous People's Health and Nutrition } \\
\text { in Brazil: rationale, methodology, } \\
\text { and overview of results }\end{array}$ & $\begin{array}{l}\text { Coimbra CEA } \\
\text { et al. }\end{array}$ & Brasil & 2013 & $\begin{array}{l}\text { Síntese de estudo trans- } \\
\text { versal de base populacio- } \\
\text { nal nacional e comparação } \\
\text { com literatura }\end{array}$ & Cerca de 200 etnias \\
\hline $\begin{array}{l}\text { Aspectos socioculturais de vacina- } \\
\text { ção em área indígena }\end{array}$ & Garnelo L. & Brasil & 2011 & $\begin{array}{l}\text { Observação participante } \\
\text { das práticas sanitárias } \\
\text { à luz da antropologia da } \\
\text { doença e da teoria da } \\
\text { representação social }\end{array}$ & Baniwa \\
\hline $\begin{array}{l}\text { A classificação dos domicílios } \\
\text { 'indígenas' no Censo Demográfico } \\
\text { 2000: subsídios para análise das } \\
\text { condições de saúde }\end{array}$ & Marinho GL. & Brasil & 2010 & $\begin{array}{l}\text { Transversal a partir de base } \\
\text { de dados secundária (Cen- } \\
\text { so Demográfico 2000) } \\
\text { com análise }\end{array}$ & - \\
\hline $\begin{array}{l}\text { Infant and young child feeding in } \\
\text { the Peruvian Amazon: the need to } \\
\text { promote exclusive breastfeeding } \\
\text { and nutrient-dense traditional } \\
\text { complementary foods }\end{array}$ & $\begin{array}{l}\text { Roche ML, } \\
\text { Creed-Kanashi- } \\
\text { ro HM, Tuesta I, } \\
\text { Kuhnlein HV. }\end{array}$ & Canadá e Peru & 2010 & $\begin{array}{l}\text { Transversal. Entrevistas } \\
\text { com informantes-chave, } \\
\text { composição de tabela } \\
\text { de ingestão calórica e } \\
\text { acompanhamento antro- } \\
\text { pométrico }\end{array}$ & Awajún \\
\hline $\begin{array}{l}\text { Cárie dentária e necessidade de } \\
\text { tratamento odontológico entre os } \\
\text { índios Baniwa do Alto Rio Negro, } \\
\text { Amazonas }\end{array}$ & $\begin{array}{l}\text { Carneiro MCG } \\
\text { et al. }\end{array}$ & Brasil & 2008 & $\begin{array}{l}\text { Transversal. Entrevistas } \\
\text { com a equipe de saúde } \\
\text { bucal local }\end{array}$ & Baniwa \\
\hline $\begin{array}{l}\text { Regionalização em Saúde no Ama- } \\
\text { zonas: avanços e desafios }\end{array}$ & $\begin{array}{l}\text { Garnelo L, Sou- } \\
\text { sa ABL, Silva } \\
\text { CO. }\end{array}$ & Brasil & 2017 & $\begin{array}{l}\text { Estudo de caso. Pesquisa } \\
\text { qualitativa, descritivo-a- } \\
\text { nalítica }\end{array}$ & - \\
\hline $\begin{array}{l}\text { The Socioeconomic Factors and the } \\
\text { Indigenous Component of Tubercu- } \\
\text { losis in Amazonas }\end{array}$ & $\begin{array}{l}\text { Castro DB, Pinto } \\
\text { RC, Albuquer- } \\
\text { que BC, Sadahi- } \\
\text { ro M, Braga JU. }\end{array}$ & & 2016 & $\begin{array}{l}\text { Ecológico baseado em } \\
\text { dados secundários da } \\
\text { vigilância epidemiológica } \\
\text { da tuberculose }\end{array}$ & - \\
\hline $\begin{array}{l}\text { The influence of socioeconomic } \\
\text { factors on traditional knowledge: a } \\
\text { cross scale comparison of palm use } \\
\text { in northwestern South America }\end{array}$ & $\begin{array}{l}\text { Paniagua- } \\
\text {-Zambrana NY, } \\
\text { Camara-Lerét R, } \\
\text { Bussmann RW, } \\
\text { Macía MJ. }\end{array}$ & & 2014 & Triangulação de métodos & Tikuna \\
\hline $\begin{array}{l}\text { Distribuição espacial e temporal } \\
\text { da tuberculose em indígenas e não } \\
\text { indígenas de Rondônia, Amazônia } \\
\text { Ocidental, Brasil }\end{array}$ & $\begin{array}{l}\text { Melo TEMP, } \\
\text { Resendes APC, } \\
\text { Souza-Santos R, } \\
\text { Basta PC. }\end{array}$ & Brasil & 2012 & $\begin{array}{l}\text { Ecológico de dados agre- } \\
\text { gados por áreas. }\end{array}$ & - \\
\hline $\begin{array}{l}\text { Condições sanitárias e socioam- } \\
\text { bientais em lauaretê, área indígena } \\
\text { em São Gabriel da Cachoeira, AM }\end{array}$ & Gaiatti LL et al. & Brasil & 2007 & $\begin{array}{l}\text { Triangulação de métodos } \\
\text { com georreferenciamento, } \\
\text { mapas falantes e observa- } \\
\text { ção participante. }\end{array}$ & - \\
\hline $\begin{array}{l}\text { Aproximación a la niñez indígena } \\
\text { de Colombia-Saberes y prácticas } \\
\text { en salud }\end{array}$ & $\begin{array}{l}\text { Ochoa-Acosta } \\
\text { EM, Quintero- } \\
\text {-Mejía M. }\end{array}$ & Colômbia & 2018 & $\begin{array}{l}\text { Revisão de fontes primá- } \\
\text { rias e secundárias }\end{array}$ & - \\
\hline $\begin{array}{l}\text { Epidemiology and economic impact } \\
\text { of cervical cancer in the state of Ro- } \\
\text { raima (Brazilian amazonic region): } \\
\text { The perspective of Brazilian unified } \\
\text { health system }\end{array}$ & $\begin{array}{l}\text { Balbinotto } G \text {, } \\
\text { Jardim A. }\end{array}$ & Brasil & 2012 & $\begin{array}{l}\text { Transversal a partir de base } \\
\text { de dados secundária (base } \\
\text { de dados de exames histo- } \\
\text { patológicos) com análise. }\end{array}$ & - \\
\hline
\end{tabular}

Fonte: Elaboração própria, com auxílio do software Atlas.ti. 


\section{Discussão}

O Distrito Sanitário Especial Indígena do Alto Rio Solimões tem uma população de cerca de 54 mil indígenas, divididos por treze etnias: Aconã, Ahanenawa, Hengatúm, Kaixana, Kambeba, Kanamari, Kocama, Maku, Marubo, Mayoruna, Ticuna, Tukano, Witoto. São 189 aldeias, situadas em sete municípios. O Distrito Sanitário Especial Indígena do Alto Rio Negro tem uma população de 36.390 indígenas, distribuídos pelas seguintes etnias: Ahanenawa, Amawáka, Arapaço, Arara, Baniwa, Bara, Barasána, Bare, Columbiara, Cubeu, Curipako, Daw, Dessano, Hupde, Hupdes, Juriti, Karapana, Kaxinawa, Kaxinawá, Kokama, Maku, Makuna, Makunambé, Makuxi, Miranha, Miriti tapuia, Munduruku, Onça, Paumari, Pirata, Piratuapuia, Silcy-tapuya, Siriano, Siuci, Tapuia, Tariano, Tatu, Tatú, Ticuna, Tukano, Tupi, Tuyuka, Wanano, Wapixana, Warekena, Wayana, Yanomami, Yepamassã, Urubu, conforme dados públicos de 2013, disponibilizados na internet pela Divisão de Atenção à Saúde Indígena (Diasi), da Secretaria Especial de Saúde Indígena, do Ministério da Saúde (Sesai/MS). São 669 aldeias, localizadas em três municípios.

$\mathrm{O}$ acesso ao interior na maior parte desses municípios nos dois DSEI é feito apenas por via fluvial. Ambas as sedes dos DSEI contam com internet, núcleos de telessaúde, Casa de Saúde Indígenas (Casai) e coordenam polos-base de atendimento nas aldeias. Tabatinga e São Gabriel da Cachoeira, respectivamente, são sedes desses DSEI, ambas metrópoles urbanas encravadas na floresta amazônica, em que essas etnias buscam atendimento do Sistema Único de Saúde (SUS). Os territórios desses distritos fazem fronteira com a Colômbia (Tabatinga faz fronteira com Letícia, formando uma conurbação urbana de tríplice fronteira), Venezuela e Peru. Essas nações originárias ocupam o território pelo ecossistema. Sua estrada é o rio, que perpassa as demarcações, fronteiras administrativas e geopolíticas entre países.

\section{Aspectos da vida de gestantes, mães e bebês indígenas na Amazônia}

Para compreender a segurança alimentar e nutricional desses povos, é preciso considerar questão contemporânea apontada pelo Instituto Brasileiro de Geografia e Estatística (IBGE). Segundo análise sobre as tendências demográficas dos indígenas ${ }^{\mathbf{1 2}}$, há frentes/ movimentos de expansão territorial externa e interna que contribuem para extinguir ou diminuir sensivelmente as terras indígenas demarcardas na Amazônia.

A frente externa considera a fronteira enquanto zona de integração econômica e de interpenetração de culturas, na qual a implantação da infraestrutura continental latino-americana é crucial. A frente interna traduz o movimento de crescimento horizontal da fronteira agropecuária com a área de expansão da rede física que a acompanha, denominada Arco do Desmatamento. A presença de significativos interesses econômicos em áreas nas quais a expansão da fronteira econômico-produtiva está acontecendo ameaça a integridade das terras indígenas existentes e dos grupos que habitam nelas com sua ocupação do solo seminômade, seguindo os rios. As cidades e as fronteiras atraem quem busca uma porta de entrada para o modo de vida ocidental nesses grupos.

Apesar dos dados alarmantes do I INSNPI, sua análise aponta o beneficiamento de mulheres e crianças indígenas no território brasileiro com políticas de transferência de renda para população vulnerável da última década e o aperfeiçoamento do cuidado com a criação da Secretaria Especial de Atenção Indígena, no âmbito do Ministério da Saúde brasileiro ${ }^{\mathbf{1 3}}$.

As entrevistas com as 2663 crianças da região norte no I INSNPI foram feitas com auxílio de um tradutor em mais de $40 \%$ dos casos. A proporção de crianças sem certidão de nascimento foi elevada, onde cerca de uma em cada cinco crianças não possuía esse documento. Um terço das crianças nasceu em um hospital, e 66,6\% 
na aldeia. Poucas nasceram nas Casas de Saúde Indígena: 8, ao todo. A proporção de baixo peso ao nascer (abaixo de 2,5 kg) foi de $4 \%$, e de cesarianas foi baixa também. Mais de $30 \%$ dos pais entrevistados não receberam informação sobre peso ao nascer e desenvolvimento dos filhos.

A maior parte das internações registradas ocorreu por diarreia e doenças respiratórias, confirmadas por outros estudos recuperados na revisão ${ }^{14,15}$. A maior proporção de casos de tuberculose em menores de 15 anos indica transmissão ativa e infecção recente nas aldeias, sugerindo que o controle dos contatos não está sendo realizado de forma satisfatória pela rede de cuidados, em estudo desenvolvido em Rondônia. Assinala-se que o pré-natal é uma oportunidade ímpar para tratar a tuberculose no núcleo familiar que convive na residência ${ }^{16}$.

Outro fator desse contexto são os grandes deslocamentos para o recebimento do recurso do Bolsa Família, que influenciam a dinâmica de ocupação do território indígena. São longas viagens que separam famílias temporariamente e influenciam o ritmo seminômade de algumas etnias. São domicílios provisórios, que não estão bem caracterizados pelo censo nacional17. Pesquisa cujo objetivo foi compreender a relação entre mudança econômica (trabalho assalariado, aposentadoria e programa Bolsa Família) e padrões alimentares na Amazônia rural e determinar até que ponto essas mudanças seguiram o padrão da transição nutricional sugere que devem ser feitos ajustes na forma como os programas de transferência condicionada de renda são administrados em populações rurais de subsistência ${ }^{\mathbf{1 8}}$.

Isso é necessário para assegurar que os objetivos principais do programa, reduzir a pobreza e a insegurança alimentar, sejam alcançados. Segundo as mulheres entrevistadas, o abandono das plantações de mandioca foi associado ao aumento da dependência de alimentos comprados, enquanto o recebimento do Bolsa Família foi associado a aumento da ingestão e adequação de proteínas. Conforme relatos de profissionais de saúde coletados em visita de campo nas duas metrópoles amazônicas brasileiras, o modo como essa política foi implantada para a população indígena agrava problemas sociais nos centros urbanos amazônicos, tais como o alcoolismo entre homens e mulheres e o surgimento de 'atravessadores' do benefício, cujo cadastro só pode ser feito por internet.

Quase 70\% dos domicílios entrevistados no I INSNPI não têm acesso à energia elétrica, ou a têm de maneira descontínua. Porém, a internet já chegou a aldeias isoladas e às cidades observadas. Smartphones são utilizados pelos indígenas, principalmente os mais jovens, em várias situações ${ }^{19}$. Um ciberativismo nascente entre essa população e a população ameríndia em geral já está registrado nas redes sociais (o Departamento de Mulheres da Federação das Organizações Indígenas do Rio Negro - FOIRN utiliza amplamente página no Facebook para divulgar seus eventos culinários e de venda de artesanto típico, vide http://www.facebook.com/FOIRN/) e em outros estudos 20 .

Na Colômbia, o Inquérito Nacional da Situação Nutricional (Ensin) de 2010 destaca a iniquidade na segurança alimentar das comunidades indígenas, expressa em atraso na estatura, deficiência de ferro, vitamina A e zinco em crianças menores de cinco anos de idade, e anemia em mulheres grávidas, maiores do que aquelas apresentadas em uma população não indígena, assim como no Brasil.

Embora perto do Oceano Pacífico e a 990 quilômetros da Amazônia brasileira, a pesquisa com 48 famílias na reserva indígena La Gabriela apresenta questões similares: mudanças nas práticas alimentares devido à influência externa afetam a autonomia e geram dependência de cadeias comerciais fortalecidas pelo livre mercado. É necessário, segundo os autores, formular políticas que fortaleçam crenças, costumes e tradições ancestrais, o que requer maior atenção por parte das entidades e dos governos estaduais ${ }^{21}$. 


\section{Cultura alimentar e nutricional de mulheres indígenas durante o perío- do gestacional e no puerpério}

A base da alimentação desses povos na floresta é a mandioca (Manihot esculenta Crantz) e seus derivados (em especial, a farinha) ${ }^{\mathbf{1 8}}$, frutos silvestres, peixes e carnes de caça. Equipes de saúde, garimpeiros, seringalistas, comerciantes, missionários, militares que circulam pela região do Alto Rio Negro observam que gêneros alimentícios industrializados fazem parte do dia a dia, numa prática de escambo. Um exemplo é a troca da iguaria típica e já turística, o peixe moqueado, pelo açúcar refinado. Os que têm alguma fonte de renda usam uma parte dela para a compra de alimentos industrializados, geralmente em São Gabriel da Cachoeira, segundo estudo de condições da saúde bucal entre a população Baniwa do polo-base de Tunuí-Cachoeira ${ }^{22}$.

Como aspectos de segurança alimentar, destacam-se na literatura recuperada: a venda de artesanato e a comida tradicional no Rio Negro, oriundas de um associativismo feminino, e a agricultura de subsistência na Colômbia.

As comidas tradicionais que fazem parte da história dessas civilizações, de sua saúde e sobrevivência também são alvo de cobiça industrial pelo seu valor nutricional. As mulheres indígenas que cozinham esses alimentos têm compreendido essa lógica e trabalhado seu saber como produto em feiras artesanais. No livro de receitas que exibe a culinária tradicional das comunidades do Alto Rio Negro, narrado pelas mulheres, percebe-se fortemente essa questão. Registra-se nele o incentivo ao associativismo feminino indígena. Há preocupação das mulheres com as mudanças nas práticas alimentares tradicionais, alimentos industrializados caros aos quais nem todos têm acesso e com baixo valor nutricional. $\mathrm{O}$ livro resgata a voz das mulheres líderes de associações femininas no espaço urbano. Há um grande contingente de mulheres que criam seus filhos sozinhas na cidade ${ }^{\mathbf{2 3}}$.

Nas aldeias, o espaço culinário é quase inalterado pelo contato interétnico, segundo observação dos autores. Os pratos mais complexos, como o pudali, são menos feitos, pela simplificação do cardápio direcionado à família, o que dificulta o ensino para as mulheres mais jovens. Esse estudo, resultante da pesquisa de dois anos junto a lideranças femininas indígenas da região do Alto Rio Negro, congrega receitas da roça, com modo de preparo narrado por essas mulheres. Narra, também, pela visão dos pesquisadores, quais alternativas econômicas e sociopolíticas elas traçaram, vendendo comidas tradicionais e artesanato nos mercados urbanos. Há quinhapiras (receita com pimenta local), mingaus de frutas, beijús e a feitura de galinha caipira para crianças pequenas. A presença da castanha em várias receitas é destaque desse texto. Na visita de campo, foram visitadas feiras em ambas as cidades, onde as pessoas das aldeias trocam receitas e vendem parte de sua agricultura de subsistência (figura 3). 
Figura 3. Mulher da etnia Kokama com barraca de frutas, legumes, variedades de banana e mandiocas regionais de sua roça na feira, próxima ao porto, em Tabatinga (AM)

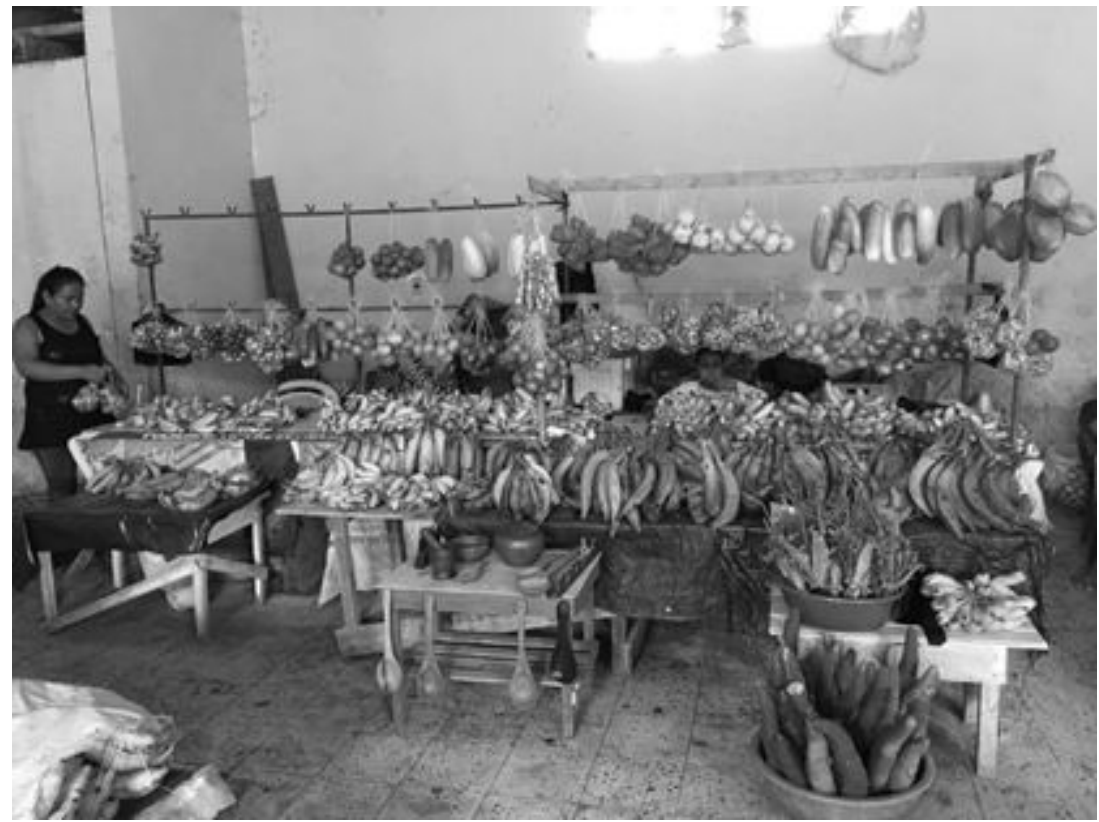

Fonte: Os autores. Registro de campo, abril 2018

Em estudo que investiga padrões sobre como populações indígenas na Amazônia, em países diversos, conseguem lidar com as plantas, usando seu conhecimento tradicional ${ }^{24}$, pode-se também observar a relação entre a agricultura de subsistência, a roça e os mercados urbanos no cotidiano desses povos. Os 14 fatores socioeconômicos estudados foram: sexo, idade, etnia, educação, idioma falado, condições de migração, tempo de permanência no território e no nível do domicílio (tamanho da família, posse de animais de fazenda, tamanho da fazenda, ferramentas, transporte, tamanho da casa, materiais de construção da casa). Autores utilizaram como proxy as palmeiras (Arecaceae), pois elas têm usos variados nas diversas etnias. Consideraram dois tipos de informantes para entrevistas em profundidade: os especialistas, indicados pela comunidade, e os comuns. Tikunas na Colômbia, oriundos da etnia que também vive em terras brasileiras, foram entrevistados. Entre seus achados, descobriram que pessoas com baixo poder aquisitivo têm grande conhecimento sobre a palmeira. Homens demonstraram mais conhecimento do que mulheres sobre as diferentes espécies. O uso principal é para culinária. O conhecimento é passado oralmente. Hipótese levantada na discussão é que existe uma perda de interesse em conhecimento tradicional de plantas e outros recursos naturais. Isso pode ocorrer devido à disponibilidade de produtos industrializados que as pessoas podem acessar, atrelada simbolicamente à disponibilidade de oportunidades de inserção social, como trabalho assalariado, agricultura orientada para o comércio ou migração para centros urbanos.

\section{A dieta dos bebês indígenas com ida- de entre 0 e 5 anos}

Mesmo sendo mamíferos, entre os seres humanos, é consenso que o ato de amamentar é um híbrido natureza-cultura ${ }^{25}$, tendo diversas nuances de acordo com as sociedades e o contexto temporal ${ }^{26}$. A percepção das etnias com relação à amamentação e aos hábitos alimentares ancestrais entre 
mulheres e seus bebês frente à aculturação é citada em oito artigos, porém, é superficialmente explorada e medida como uma possível causa da desnutrição nessa população.

A literatura indica que há embate e interesses diversos no discurso feminino indígena sobre o desmame precoce e a entrada desse bebê no mundo ocidentalizado, que necessita ser melhor investigado. Um exemplo é o estudo longitudinal recuperado que foca na amamentação exclusiva e complementar de população da Amazônia boliviana. Considerados portadores da melhor saúde cardiovascular do mundo ${ }^{27}$, os Tsimane habitam um ecossistema similar ao das comunidades de Alto Rio Negro e Tabatinga: florestas, clima equatorial, 15 mil indígenas distribuídos em 90 aldeias ribeirinhas com acesso a centros urbanos $^{28}$. Autores pesquisaram nove aldeias e 161 famílias durante um ano. Medidas antropométricas, entrevistas e checagem da dieta foram feitas. Resultados sugerem surpreendentemente que a introdução da alimentação complementar na dieta do recém-nascido tem a ver com a necessidade de aumentar a família e que a amamentação exclusiva extendida adiaria novas gestações desejadas pela mulher ${ }^{29}$.

O livro de receita das populações do Alto Rio Negro $^{23}$ apresenta 57 receitas do sistema alimentar baniwa, baré, piratapuia, tukano, cuewana, kubeo e dessana, divididas em: peixes e caças; beijus; mingaus (especialmente relevantes na introdução de alimentos sólidos aos bebês); molhos, temperos e outros acompanhamentos; doces e bebidas. As receitas de peixe moqueado, de cudiari, arubé, chibé, pimenta jiquitaia, vinho de pupunha, de açaí, de patauá e de buriti são comuns a todas as etnias. O livro apresenta 30 receitas de maneira bilíngue (português e baniwa).

A introdução de alimentos sólidos ao bebê é uma oportunidade ímpar a ser explorada pelos profissionais de saúde, pois o manejo adequado dos alimentos pode evitar casos de diarreia nas crianças e posteriores hospitalizações, decorrentes de desidratação. Além disso, é necessária a distribuição do soro e informação sobre a terapia de reidratação oral em língua nativa e respeitando os saberes tradicionais, $o$ que necessariamente não envolve distribuição de sal e açúcar industrializado. A redução na prevalência de diarreia depende de melhorias nas condições de saneamento e de higiene na preparação dos alimentos, como também do aumento da mediana da amamentação exclusiva.

A amamentação teve um efeito protetor para diarreia apenas nos primeiros três meses de vida dos bebês na macrorregião Norte, segundo resultados do I INSNPI. Uma vez que essas crianças moram em condições precárias de higiene, provavelmente os alimentos introduzidos na dieta estão contaminados e causam a diarreia.

As famílias cuja criança tem tosse ou diarreia procuram auxílio junto ao curador, pajé (20,8\%); ao agente de saúde indígena (46\%); e no polo-base na aldeia (69\%). O inquérito sugere que o programa de suplementação com sulfato ferroso não está atingindo o seu objetivo, já que apenas uma em cada cinco crianças menores de cinco anos recebeu pelo menos uma dose de sulfato ferroso nos três meses anteriores à coleta de dados. Há uma prevalência de baixa estatura para idade de $33,8 \%$. Os dados coletados levam a crer que esse indicador tem um incremento na época do começo do desmame e introdução de alimentos sólidos, pois foram encontradas $66 \%$ de crianças com anemia nesse período do ciclo de vida.

A literatura posterior a 2014 explora alguns limites do inquérito. Revisão discute que esse primeiro inquérito não considerou a determinação tridimensional, abrangendo os fatores socioeconômicos, etários e étnicos da população investigada. O contexto cultural como fator determinante do estado nutricional de populações indígenas explica-se em função da diversidade ecológica, social e cultural desses povos; e das influências nas condições de saúde e de vida dessas populações, decorrentes do processo de aculturação. Além disso, determinantes importantes do estado nutricional, como os hábitos alimentares, as práticas de cuidado, a amamentação e o desmame, apresentam variada dimensão cultural e ritualística entre as sociedades indígenas. Importante constatação é que nenhum dos trabalhos sistematizados por essa revisão abordou as práticas de cuidados e o acesso aos serviços primários de saúde ${ }^{30}$. 
Curiosamente, estudo desenvolvido com 32 mães e bebês do maior povo indígena peruano, denominado Awajún, vai apontar questões muito importantes sobre o valor nutricional do alimento industrializado versus alimentação tradicional ${ }^{31}$. Metade dos bebês foi amamentada exclusivamente até os seis meses. $\mathrm{O}$ estudo descreve $\mathrm{o}$ aleitamento e as práticas de alimentação complementar de bebês e crianças abaixo de dois anos de idade, considerando o papel da alimentação tradicional. Ela é concebida como todas as comidas aceitáveis e advindas dos recursos naturais de um determinado grupo cultural.

A prevalência de desnutrição em crianças abaixo de três anos foi de $33,4 \%$ e de $65 \%$ para anemia no distrito da Amazônia peruana, onde essa população vive num regime de subsistência ao longo do rio Marañon. Pesquisadores criaram uma lista de comidas tradicionais através de entrevistas com informantes-chave e grupos focais. Essa lista foi base para desenvolvimento de uma tabela de composição de alimentos para ser utilizada no cálculo da ingestão dietética. Comidas tradicionais forneceram $85 \%$ de energia e se mostraram mais completas em nutrientes do que os alimentos industrializados. Entre seus achados, destaca-se que a amamentação exclusiva por seis meses precisa ser promovida nas comunidades estudadas. Como no Brasil, leite em pó fornecido pelo governo é dado para os bebês abaixo de seis meses.

Dado o declínio do estado nutricional documentado nos primeiros dois anos de vida, há necessidade de intervenções nutricionais para os Awajún ingerirem alimentos complementares, densos em nutrientes, alimentos locais saudáveis. Comidas locais tradicionais, especialmente leite materno e alimentos de origem animal, precisam ser promovidas em detrimento dos alimentos de mercado e comerciais em suas embalagens coloridas, mas com menos vantagens nutricionais, que estão cada vez mais disponíveis na comunidade.

A promoção da saúde com alimentos tradicionais precisa incluir políticas que protejam o acesso e a disponibilidade de alimentos animais e vegetais culturalmente apropriados; essas políticas precisam incluir proteção e demarcação da terra para uso pelos Awajún, segundo os autores. Concebe-se agroecologia como uma disciplina científica que enfoca o estudo da agricultura sob uma perspectiva ecológica e com um marco teórico cuja finalidade é analisar os processos agrícolas de forma abrangente. A Articulação Nacional de Agroecologia reúne diversos atores no Brasil, inclusive profissionais de saúde e indígenas. As redes do movimento agroecológico no Brasil e as mulheres indígenas estão atentas a esse problema, conforme revelam registros de fala do encontro Mulheres Indígenas e Segurança Alimentar e Nutricional ${ }^{32}$ :

Iranilde Barbosa dos Santos, da etnia Macuxi, representando o Norte do País, ressaltou que cada povo tem seu jeito de preparar a comida e fazer suas refeições e que, por isso, a partilha desses conhecimentos é fundamental. Falou sobre as mudanças na alimentação, com a introdução de alimentos industrializados e refrigerantes nas comunidades indígenas. Apesar de alguns povos ainda manterem suas práticas alimentares tradicionais, é mais comum encontrar nas aldeias alimentos comprados em mercados, especialmente em razão da falta de acesso aos seus territórios e recursos naturais. Ela defendeu que o Programa de Aquisição de Alimentos (PAA) direcionado às mulheres pode ser uma boa alternativa para evitar o consumo de alimentos industrializados, pois o Programa fomenta a produção de alimentos de acordo com sua cultura e biodiversidade territorial, promovendo, assim, uma alimentação mais saudável nas aldeias.

\section{Profissionais da atenção básica e cul- tura alimentar e nutricional indígena}

Pesquisas realizadas nos DSEI em todo Brasil ${ }^{33}$ apontam três questões: o desconhecimento das culturas indígenas e da historicidade que permeia a vida contemporânea nessas sociedades; o despreparo para lidar com a alteridade; e a homogeneização das práticas sanitárias 
calcadas em ações biomédicas de baixa resolutividade e elevada descontinuidade.

Estudo sobre projetos de atenção primária voltados à população indígena em Rio $\operatorname{Branco}^{34}(\mathrm{AC})$ dá destaque ao conhecimento das mulheres sobre plantas medicinais e como elas se empoderam na comunidade, mesmo morando na cidade. Nesse artigo, o autor argumenta que os formuladores de políticas devem prestar atenção às relações entre autoridade, gênero e conhecimento local, e examinar como o uso desse conhecimento pode auxiliá-los no cuidado.

Estudo de caso sobre o processo de regionalização em saúde registra que a capital Manaus monopoliza os sistemas de abastecimento, transporte, provisão de serviços e a condução da vida política, num cenário de fraco protagonismo dos outros municípios e de interação rarefeita entre eles. $\mathrm{O}$ isolamento geográfico alegado mascara a falta de habilidade dos gestores de organizar as redes regionais de atenção e buscar financiamento. Essa estrutura colabora para o cenário de uma atenção primária deficiente para a população indígena, que está mais na dimensão xamânica ${ }^{35}$, sendo essa a influência principal da percepção e enunciação infantil do processo saúde-doença ${ }^{36}$.

Atendimentos são feitos em viagens periódicas, percorrendo grandes distâncias. Concepções coletivas de doença geram estratégias terapêuticas igualmente coletivas, e é dessa forma que se organizam o xamanismo e outras modalidades nativas de cuidados com a saúde entre essas populações. Trata-se de importante ponto de divergência entre a biomedicina e as práticas tradicionais de cuidado, segundo os pesquisadores desse estudo sobre vacinação. Falta de pontualidade e descumprimento de acordos por parte das equipes de saúde costumam ser interpretados como resultantes de decisões individuais dos profissionais, que passam a ser encarados como pessoas que não honram a palavra. As prioridades deles são estabelecidas em torno da roça, das festas, dos atos religiosos, da convivência doméstica e do respeito à autonomia e à liberdade das crianças. Ação curativa é priorizada pela comunidade nesse contexto, e evitar a doença para os indígenas é restabelecer a paz social ${ }^{37}$.

Iniciativa em área indígena localizada a noroeste do Amazonas, na sede do distrito de Iauaretê, com quase três mil habitantes, cerca de 440 domicílios com representantes de 15 etnias, sendo a maioria Tariano ou Tukano, e que está na fronteira com a Colômbia, na confluência dos rios Papuri e Waupés, traz achados que vão ao encontro dos estudos de Garnelo, em que a explicação para a doença na visão indígena mixa o biomédico/sanitário e o mitológico.

Há a presença curativa do pajé, primeiramente, e depois da equipe de saúde para esses povos. A atenção primária está carregada de aspectos mitológicos e ritualísticos, dimensões das benzedeiras e xamãs. $O$ autor destaca que a maioria das áreas indígenas não recebe o devido saneamento no Brasil e que a situação na região Norte, onde há uma maior diversidade étnica, é ainda pior, visto que nessa região estão os piores indicadores de saneamento básico do País. Documenta o saneamento precário na região e a ausência do poder público, visto que não há o mínimo de estrutura para a população ${ }^{38}$.

Um quarto das crianças pesquisadas no inquérito nasceu por mão de parteiras nas aldeias. No entanto, a figura da parteira se mostra subalterna na atenção da saúde pública, mesmo sendo conhecido que o papel social das parteiras é maior do que a atuação técnica na gestação e no parto. As parteiras exercem protagonismo político junto às demandas por melhorias na qualidade de vida da comunidade, sendo a figura feminina entre o mitológico e a biomedicina nesses povos ${ }^{39,40}$.

Embora as unidades de telessaúde desempenhem papel fundamental nas ações de educação permanente do SUS no estado do Amazonas ${ }^{41}$, percebe-se pouco uso dessa ferramenta pela rede de atenção à saúde indígena brasileira.

O Sistema de Atenção à Saúde Indígena tem quadros insuficientes para dar resposta e fazer cumprir os princípios do SUS para a população indígena, conforme outro estudo. A incapacidade dessa secretaria do Ministério da Saúde brasileiro em prover diretamente a atenção à saúde da população indígena sob 
sua responsabilidade sanitária contribui para continuação da estratégia de terceirização das ações, mediante a adoção de convênios ou de compra de serviços de entidades não governamentais e de sistemas municipais de saúde ${ }^{33}$. Segundo o autor, é necessário um olhar diferenciado, a fim de investigar o perfil de iniquidades nutricionais apontado pela literatura pregressa na região amazônica, onde o maior percentual de terras demarcadas e de cobertura vegetal nos levaria a esperar melhores níveis nutricionais. As três metrópoles amazônicas observadas em visita de campo confirmam os achados dessa afirmação sobre as redes de atenção. Não foi identificada uma política de assistência para indígenas advindos da Colômbia (figura 4), e existe uma divisão informal entre os indígenas da aldeia, que vão ser tratados na Casai, e os que moram nas cidades e são atendidos nas unidades básicas de saúde.

Figura 4. Em sentido horário, acima Casai do DSEI Alto Rio Negro/MS (São Gabriel da Cachoeira/AM), Casai do DSEI Alto Rio Solimões/MS e unidade de saúde da prefeitura (Tabatinga/AM), onde se localiza o núcleo de telessaúde da cidade, todas em perímetro urbano e que recebem indígenas
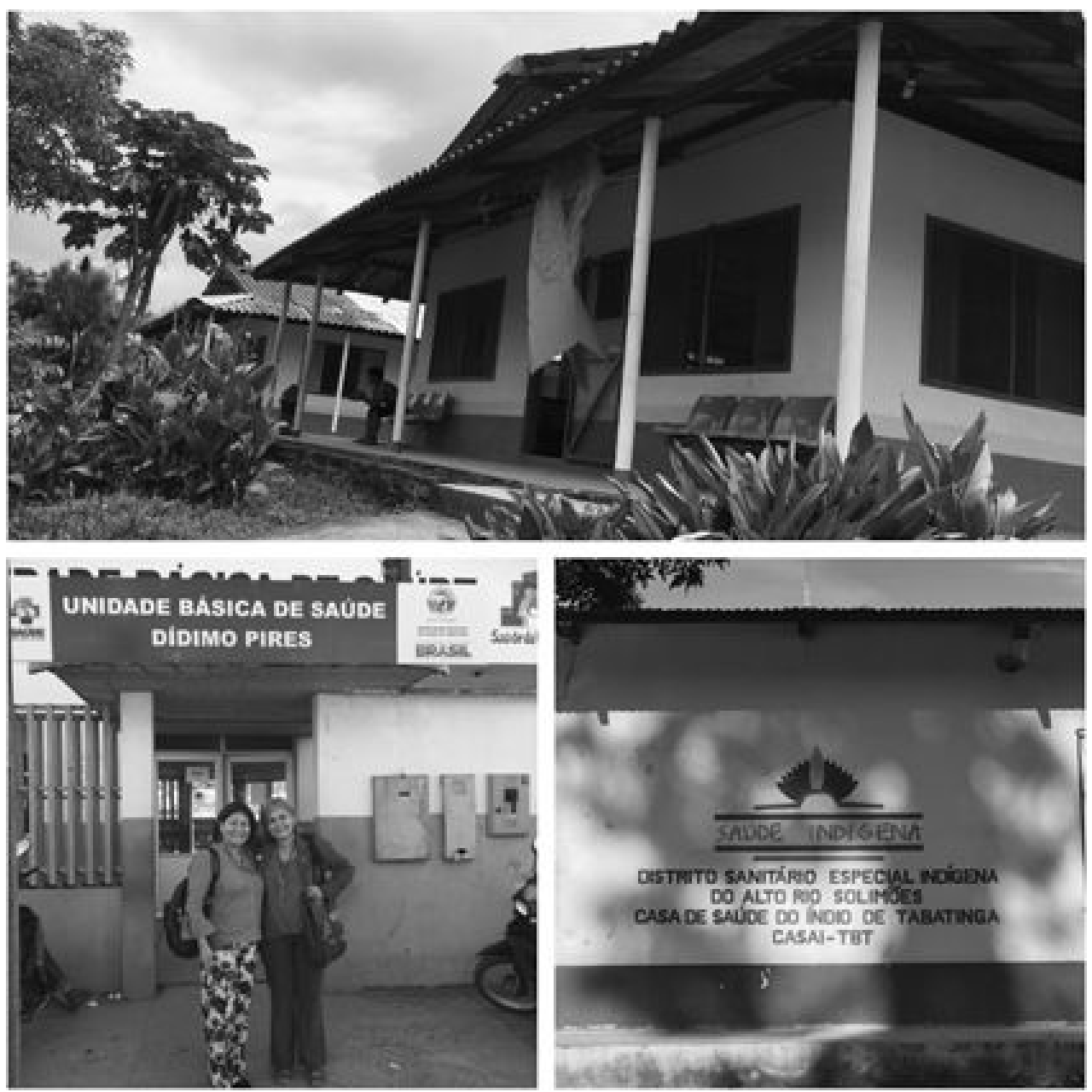

Fonte: Os autores. Registro de campo, abril 2018 
Em relatório divulgado pela Associação Brasileira de Saúde Coletiva (Abrasco) ${ }^{\mathbf{4 2}}$, os resultados do I INSNPI estão agregados para toda a região Norte e revelam algumas nuances desse cuidado. Mulheres e crianças do território (DSEI Alto Rio Negro e DSEI Alto Rio Solimões) da pesquisa que motivou essa revisão correspondem a cerca de $22 \%$ do universo pesquisado. Nas entrevistas em profundidade, há uma parte dedicada à mulher e outra à criança. Foi necessário o auxílio de tradutores em $35,7 \%$ das entrevistas realizadas na região Norte, o que denota uma forte herança linguística nessas etnias habitantes do território amazônico. Mais de 64,7\% dessas indígenas $(\mathrm{n}=2574)$ estavam entre 14 e 29 anos, portanto, eram bem jovens à época.

A maioria respondeu sobre sua vida e de seus filhos. Apenas 18 mulheres desse grupo possuíam graduação, nenhuma pós-graduada e mais de $70 \%$ se alfabetizaram, parando na quarta série do ensino regular. Tanto os níveis glicêmicos sugestivos de diabetes mellitus quanto a medição de pressão arterial foram menores na região Norte, comparada a outras regiões. A anemia foi avaliada pela dosagem de hemoglobina. A prevalência da anemia na região Norte de mulheres grávidas e não grávidas é de 46\%. 101 mulheres foram encontradas com anemia grave. $31 \%$ das mulheres estão entre o sobrepeso e a obesidade. Um quarto dessas mulheres recebeu tratamento contra a malária nos meses anteriores à entrevista.

Quanto à caracterização do pré-natal do filho vivo mais novo, cerca de $25 \%$ dessas mulheres não frequentaram o pré-natal. O número aumenta para a gravidez tardia ( 45 a 49 anos), em que essa ausência chega a quase $40 \%$. As que vão têm uma média de três consultas durante a gravidez, quando o recomendado pelo MS é a realização de, no mínimo, seis consultas. Mais de $50 \%$ iniciam seu pré-natal no segundo trimestre da gravidez. O cuidado pré-natal das mulheres dessa região é aquele no qual há a menor proporção de pedidos de exames, variando de $2,2 \%$ para sorologia para rubéola a $32,6 \%$ para teste sorológico para sífilis (Venereal Disease Research Laboratory - VDRL). A dificuldade de articulação da rede regionalizada de atenção pode ser uma explicação para isso.

Porém, essa carência de apoio diagnóstico pode resultar em uma série de doenças congênitas e óbitos fetais evitáveis. A região Norte apresentou menor média de csonsultas, início tardio das consultas, menores proporções de solicitação de exames fundamentais e menor proporção de suplementação de sulfato ferroso e de ácido fólico para a prevenção de anemia e de malformações do tubo neural. Constatou-se, também, que as gestantes não têm cobertura vacinal adequada de tétano e da hepatite B. Não foram encontrados registros de teleconsultoria nos estudos recuperados, embora seja modalidade de telessaúde presente no Amazonas.

A ausência/insuficiência de informação preventiva sobre a saúde do filho e a comunicação entre a mulher e a equipe de saúde são enumeradas como causas de problemas entre os habitantes das aldeias isoladas. Investigação assinala que as mulheres nas aldeias são mais propensas ao câncer de colo de útero, porque começam a vida sexual cedo, não têm acesso à informação sobre o HPV (papilomavírus humano) nem aos programas de prevenção do sistema de saúde e não usam preservativo ${ }^{43}$.

\section{Conclusões}

A transição nutricional dos indígenas é um objeto de estudo multidisciplinar, e a revisão de escopo empreendida cumpriu seu papel de iluminar os caminhos da pesquisa e elucidar brechas do conhecimento sobre o tópico, resultando na preparação das oficinas com mulheres indígenas de registro audiovisual digital da culinária tradicional. O parlamento das coisas, concebido por Latour, em que fórums híbridos apresentam a dimensão associativa entre indivíduos, coletividades e coisas, traz um enfoque teórico a ser explorado para compreender como os indígenas 
se relacionam com seu território, bem como sobre como se organizam as redes de atenção à saúde na floresta ${ }^{\mathbf{4}}$.

Sob essa perspectiva da Teoria Ator-Rede (TAR), a segurança alimentar e nutricional materializada na valorização da culinária da roça pode ser o elo feminino entre diferentes etnias. $\mathrm{E}$ a conformação da telessaúde como saúde à distância no território do Amazonas (sendo tão útil para populações isoladas e subutilizada pela saúde indígena) reflete a lacuna entre cuidador e o cuidado. Isso provavelmente não é notório para pesquisadores, gestores e profissionais, porque a pesquisa em saúde ainda precisa dar um salto da medicina flexneriana, baseada no paradigma da anatomia patológica, e rumar em direção à transdisciplinaridade, a que se propõe o campo da saúde coletiva, para cuidar dos povos originários de maneira respeitosa e mais eficaz.

Embora prevaleçam perfis epidemiológicos oriundos de estudos transversais que denunciam o precário estado de saúde da população indígena em geral, comparada aos cidadãos ocidentalizados, são escassas as pesquisas que registrem a contemporânea enunciação desses povos originários como fator de sua saúde.

Os estudos, em sua maioria, denotam um silenciamento das vozes dos sujeitos e uma perversa contenção do recente crescimento demográfico das populações indígenas com a introdução de alimentos industrializados na dieta; a manutenção de condições sanitárias insalubres e a desconsideração das tradições xamânicas alimentares específicas, ainda represadas na oralidade das diversas etnias.

Temas como a inclusão digital e a relação dos indígenas nas metrópoles amazônicas, a introdução da internet e da eletricidade nas aldeias isoladas necessitam de um mapeamento apurado, a fim de melhorar a qualidade do cuidado a essa população e para que eles efetivamente desfrutem dos princípios do SUS. Sem esse direcionamento para visão ampliada de saúde, que considera a dimensão simbólica, estudos e intervenções de saúde pública continuarão culpabilizando os povos da floresta e mascarando um extermínio lento pós-colonialista.

\section{Colaboradores}

Silva AB (0000-0003-0292-5106)* e Andrade Filha IG (0000-0003-4127-8722)* contribuíram para concepção, planejamento e para a análise e a interpretação dos dados; para a elaboração do rascunho, para a revisão crítica do conteúdo e participaram da aprovação da versão final do manuscrito. Benevides KMM (0000-0002-8315-5993)*, Silva DM (0000-0001-9531-0877)*, Rodrigues PMA (0000-0003-1171-2671)*, Silva SC (00000001-6633-6744)* e Garzón MIC (0000-00029078-8545)* contribuíram para a análise e a interpretação dos dados, revisão crítica do conteúdo bem como participaram da aprovação da versão final do manuscrito. 


\section{Referências}

1. Coimbra CE, Santos RV, Welch JR, et al. The First National Survey of Indigenous People's Health and Nutrition in Brazil: rationale, methodology, and overview of results. BMC Public Health [internet]. 2013 [acesso em 2018 jul 10]; 13(1):1-19. Disponível em: http://bmcpublichealth.biomedcentral.com/articles/10.1186/1471-2458-13-52.

2. Quermes PAA, Carvalho JA. Os impactos dos benefícios assistenciais para os povos indígenas: estudo de caso em Aldeias Guaranis. Serv. Soc. Soc. 2013; 116:769-91.

3. Carvalho ALM, Oliveira ALB, Guimarães SS. Caracterização epidemiológica das populações indígenas e do Subsistema de Saúde Indígena do Brasil: uma revisão integrativa da literatura. Bol. Inf. Geum. 2014; 5(3):72-8.

4. Orellana JDY, Santos RV, Coimbra Jr CEA, et al. Anthropometric evaluation of indigenous Brazilian children under 60 months of age using NCHS/1977 and WHO/2005 growth curves. J. Pediatr. (Rio J). 2009; 85(2):117-21.

5. Garnelo L, Welch JR. Transição alimentar e diversidade cultural: desafios à política de saúde indígena no Brasil. Cad. Saúde Pública. 2009; 25(9):1872-3.

6. Souza VMG, Villar BS. Hábitos alimentares e produtos ultraprocessados na alimentação escolar: um estudo de caso da Terra Indígena Piaçaguera, São Paulo, Brasil. Segur. Aliment. Nutr. 2018; 25(1):23-30.

7. Peterson J, Pearce PF, Ferguson LA, et al. Understanding scoping reviews: Definition, purpose, and process. J. Am. Assoc. Nurse Pract. 2017; 29(1):12-6.

8. Peters MDJ, Godfrey CM, Khalil H, et al. Guidance for conducting systematic scoping reviews. Int. J. Evid. Based Healthc. 2015; 13(3):141-6.

9. Pinheiro R, Guizardi FL. Cuidado e integralidade: por uma genealogia de saberes e práticas no cotidiano.
In: Pinheiro R, Mattos RA, organizadores. Cuidado: as fronteiras da integralidade. Rio de Janeiro: Hucitec; 2004. p. 21-36.

10. Ayres JR CM. O cuidado, os modos de ser (do) humano e as práticas de saúde. Saúde Soc. 2004; 13:16-29.

11. Minayo, MCS. Introdução. In: Minayo MCS, Assis SG, Souza ER, organizadores. Avaliação por triangulação de métodos: Abordagem de Programas Sociais. Rio de Janeiro: Fiocruz, 2010. p. 19-51.

12. Instituto Brasileiro de Geografia e Estatística. Tendências demográficas: uma análise dos indígenas com base nos resultados da amostra dos censos demográficos 1991 e 2000. Rio de Janeiro: IBGE; 2005.

13. Garnelo L. O SUS e a Saúde Indígena: matrizes políticas e institucionais do Subsistema de Saúde Indígena. In: Teixeira CC, Garnelo L, organizadores. Saúde Indígena em Perspectiva: explorando suas matrizes históricas e ideológicas. Rio de Janeiro: Fiocruz; 2014. p. 107-42.

14. Melo TEM, Resendes AP, Souza SR, et al. Distribuição espacial e temporal da tuberculose em indígenas e não indígenas de Rondônia, Amazônia Ocidental, Brasil. Cad. Saúde Pública. 2012; 28(2):267-80.

15. Viana PV, Goncalves MJF, Basta PC. Ethnic and Racial Inequalities in Notified Cases of Tuberculosis in Brazil. PLoS One. 2016; 11(5):e0154658.

16. Cardoso EC, Fernandes RAQ. Situações maternas impeditivas do aleitamento materno: uma revisão bibliográfica. Rev. Saúde UNG SER. [internet]. 2014 [acesso em 2014 jan 1]; 7(1-2):50-6. Disponível em: http://www.revistas.ung.br/index.php/saude/article/view/1372/1315.

17. Marinho GL, Santos RV, Pereira N. Classificação dos domicílios "indígenas" no Censo Demográfico 2000: subsídios para a análise de condições de saúde. Rev. Bras. Estud. Popul. 2011; 28(2):449-66. 
18. Piperata BA, Ivanova SA, Da-Gloria P, et al. Nutrition in Transition: Dietary Patterns of Rural Amazonian Women During a Period of Economic Change. Am. J. Hum. Biol. 2011; 23(4):458-69.

19. Di Felice M, Pereira E. Redes e ecologias comunicativas indígenas: as contribuições dos povos originários à teoria da comunicação. São Paulo: Paulus; 2017.

20. Aguilar PA. O protagonismo comunicacional-informacional-digital indígena na sociedade da informação: antecedentes, experiências e desafios. Anu. Electrónico Estud. Comum. Soc. Disert. 2018; 11(2):104.

21. Farfán JCC, Torres DA, Gómez MNP, et al. Condiciones de seguridad alimentaria en una comunidad indígena de Colombia. Physis [internet]. 2019 [acesso 2019 fev 25]; 28(4):e280405. Disponível em: http://www. scielo.br/scielo.php?script=sci_arttext\&pid=S0103$-73312018000400604 \& \operatorname{lng}=$ es\&tlng=es.

22. Carneiro MCG, Santos RV, Garnelo L, et al. Cárie dentária e necessidade de tratamento odontológico entre os índios Baniwa do Alto Rio Negro, Amazonas. Ciênc. Saúde Colet. 200812; 13(6):1985-92.

23. Garnelo L, Baré GB. Comidas Tradicionais Indígenas do Alto Rio Negro. Manaus. Rio de Janeiro: Fiocruz; 2009.

24. Paniagua-Zambrana NY, Camara-Leret R, Bussmann $\mathrm{RW}$, et al. The influence of socioeconomic factors on traditional knowledge: a cross scale comparison of palm use in northwestern South America. Ecol. Soc. 2014; 19(4):9.

25. Maia PRDS, Almeida JAG, Novak FR, et al. Human Milk Banks National Network: Genesis and evolution. Rede Nacional de Bancos de Leite Humano: Gen. Evol. 2006; 6(3):285-92.

26. Crivaro ET. Mulher e amamentação: atitudes reveladas para o assistir no contexto hospitalar de alta complexidade - contribuições da enfermagem [tese]. Rio de Janeiro: Universidade Federal do Rio de Janeiro; 2010. 154 p.
27. Kaplan H, Thompson RC, Trumble BC, et al. Coronary atherosclerosis in indigenous South American Tsimane: a cross-sectional cohort study. The Lancet. 2017; 389(10080):1730-9.

28. von Rueden C, Jaeggi A, Stieglitz J, et al. Growth references for Tsimane forager-horticulturalists of the Bolivian Amazon. Am. J. Phys. Anthropol. 2017; 162(3):441-61.

29. Martin MA, Garcia G, Kaplan HS, et al. Conflict or congruence? Maternal and infant-centric factors associated with shorter exclusive breastfeeding durations among the Tsimane. Soc. Sci. Med. 2016; 170:917.

30. Pedraza DF, Sales MC, Queiroz D, et al. Brazilian indigenous children: Review of studies about nutritional status. Rev Nutr-Braz J Nutr. 2014; 27(4):473-88.

31. Roche ML, Creed-Kanashiro HM, Tuesta I, et al. Infant and young child feeding in the Peruvian Amazon: the need to promote exclusive breastfeeding and nutrient-dense traditional complementary foods. Matern. Child Nutr. 2011; 7(3):284-94.

32. Relatório do Primeiro Seminário de Mulheres Indígenas e Segurança Alimentar e Nutricional [internet]. Brasília, DF: Conselho Nacional de Segurança Alimentar e Nutricional - Consea; 2013. [acesso 2019 abr 12]. Disponível em: http://www.agroecologia.org. br/files/importedmedia/relatorio-seminario-mulheres-indigenas-2014.pdf 1.

33. Garnelo L. Fórum: saúde e povos indígenas no Brasil. Posfácio. Cad. Saúde Pública. 2014; 30(4):875-7.

34. Wayland C. Gendering local knowledge: Medicinal plant use and primary health care in the Amazon. Med. Anthropol. Q. 2001; 15(2):171-88.

35. Garnelo L, Sousa ABL, Silva CO. Regionalização em Saúde no Amazonas: avanços e desafios. Ciênc. Saúde Colet. 2017; 22(4):1225-34.

36. Ochoa Acosta EM, Quintero-Mejía M. Aproximación 
a la niñez indígena de Colombia- Saberes y prácticas en salud. Rev. Latinoamericana Cien. Soc. Niñez Juventud. 2017; 16(1):43-53.

37. Garnelo L. Aspectos socioculturais de vacinação em área indígena. Hist. Cienc. Saúde Manguinhos. 2011; 18(1):175-90.

38. Giatti LL, Rocha AA, Toledo RF, et al. Condições sanitárias e socioambientais em Iauaretê, área indígena em São Gabriel da Cachoeira, AM. Ciênc. Saúde Colet. 2007; 12(6):1711-23.

39. Silva SC. Parteiras Tradicionais: atenção à gestação e ao parto em uma comunidade rural Amazônica do Município de Itacoatiara - Amazonas. [dissertação]. Manaus: Instituto Leônidas e Maria Deane, Fundação Oswaldo Cruz, Manaus; 2017. 68 p.

40. Scopel D. Uma etnografia sobre a pluralidade de modelos de atenção à saúde entre os índios munduruku na terra indígena kwatá laranjal, borba, Amazonas: práticas de autoatenção, xamanismo e biomedicina. [tese]. Florianópolis: Universidade Federal de Santa Catarina; 2013. 262 p.
41. Silva AB, Silva DA, Arreguy EEM, et al. Curso de processamento e controle de qualidade do leite humano no estado do Amazonas por telessaúde: um estudo de caso da Rede BLH do SUS. RECIS [internet]. 2013 [acesso 2013 jan 25]; 7(2). Disponível em: http:// www.reciis.icict.fiocruz.br/index.php/reciis/article/ view/725/1626.

42. Cardoso AM, Horta BL, Coimbra Jr CEA, et al., organizadores. Inquérito Nacional de Saúde e Nutrição dos Povos Indígenas. Rio de Janeiro: FUNASA; 2009.

43. Fonseca AJ, Ferreira LP, Dalla-Benetta AC, et al. Epidemiology and economic impact of cervical cancer in Roraima, a Northern state of Brazil: the public health system perspective. Rev. Bras. Ginecol. Obstet. 2010; 32(8):386-92.

44. Latour B. Por uma antropologia do centro. Mana. 2004; 10:397-413.

Recebido em 03/03/2018

Aprovado em 09/09/2019

Conflito de interesses: inexistente

Suporte financeiro: Processo 443182/2016-7 da Chamada CNPq/ MCTIC № 016/2016 - Segurança Alimentar e Nutricional no

Âmbito da Unasul 